\section{ECOPITOR}

Make Your Publications Visible.
A Service of

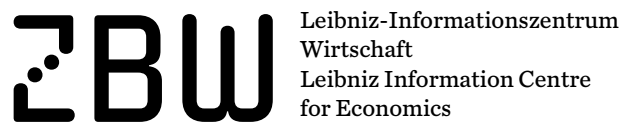

Molina, José Alberto; Iñiguez, David; Ruiz, Gonzalo; Tarancón, Alfonso

\title{
Working Paper \\ Leaders among the leaders in Economics: A network analysis of the Nobel Prize laureates
}

GLO Discussion Paper, No. 533

Provided in Cooperation with:

Global Labor Organization (GLO)

Suggested Citation: Molina, José Alberto; Iñiguez, David; Ruiz, Gonzalo; Tarancón, Alfonso (2020) : Leaders among the leaders in Economics: A network analysis of the Nobel Prize laureates, GLO Discussion Paper, No. 533, Global Labor Organization (GLO), Essen

This Version is available at:

http://hdl.handle.net/10419/216772

Standard-Nutzungsbedingungen:

Die Dokumente auf EconStor dürfen zu eigenen wissenschaftlichen Zwecken und zum Privatgebrauch gespeichert und kopiert werden.

Sie dürfen die Dokumente nicht für öffentliche oder kommerzielle Zwecke vervielfältigen, öffentlich ausstellen, öffentlich zugänglich machen, vertreiben oder anderweitig nutzen.

Sofern die Verfasser die Dokumente unter Open-Content-Lizenzen (insbesondere CC-Lizenzen) zur Verfügung gestellt haben sollten, gelten abweichend von diesen Nutzungsbedingungen die in der dort genannten Lizenz gewährten Nutzungsrechte.
Terms of use:

Documents in EconStor may be saved and copied for your personal and scholarly purposes.

You are not to copy documents for public or commercial purposes, to exhibit the documents publicly, to make them publicly available on the internet, or to distribute or otherwise use the documents in public.

If the documents have been made available under an Open Content Licence (especially Creative Commons Licences), you may exercise further usage rights as specified in the indicated licence. 


\title{
Leaders among the leaders in Economics:
}

\section{A network analysis of the Nobel Prize laureates}

\author{
José Alberto Molina ${ }^{1,4,5 *}$, David Iñiguez ${ }^{3,4}$, Gonzalo Ruiz ${ }^{4}$, Alfonso Tarancón ${ }^{2,4}$ \\ 1. Departament of Economics, University of Zaragoza, Spain \\ 2. Departament of Theoretical Physics, University of Zaragoza, Spain \\ 3. ARAID Foundation, Diputación General de Aragón, Spain \\ 4. Institute for Biocomputation and Physics of Complex Networks (BIFI), Spain \\ 5. Institute of Labor Economics (IZA), Germany
}

\begin{abstract}
We analyse the production and networks of Nobel laureates in Economics, employing the Normalized Impact Factor (NIF) of their publications in the Journal of Citation Report (Economics), to identify the academic leaders among those laureates awarded between 1969 and 2016. Our results indicate that direct collaborations among laureates are, in general, rare, but when we add all the co-authors of the laureates, there appears a very large component containing $70 \%$ of the nodes, so that more than two thirds of the laureates can be connected through only two steps. Deaton, Tirole, Arrow, and Stiglitz are identified as leaders according to the total production of their respective networks.
\end{abstract}

Keywords: Nobel prize; Economics; Impact factor; Research production; Complex networks

* Corresponding author: JA Molina. e-mail: jamolina@unizar.es 


\section{Introduction}

The winning of a Nobel Prize is the greatest success in the professional output of any researcher, which makes him/her an academic leader (Zuckerman, 1967, 1977). This success comes from individual work, but it also has a collaborative component. In this letter, we perform a production analysis of the Economics laureates from a network perspective, which allows us to analyse cooperation links among them and to identify the academic leaders among the Nobel Prize laureates according to their production, the networks generated around the laureates, or their central position in the network.

The academic literature shows that collaboration in writing papers confers advantages for the co-authors, which follow from repeated discussions and the combination of their varied skills (Sutter and Kocher, 2004; Goyal et al., 2006; Rath and Wohlrabe, 2016). Network methods, initially derived from Physics and Computational Sciences, have been increasingly applied to study scientific outputs in various fields of research, with a limited number of applications recently appearing in Economics (Polyakov et al., 2017, Araujo and Fontainha, 2017; Molina et al., 2018).

We build the networks of Nobel laureates and co-authors, and assign to each paper the Normalized Impact Factor (NIF) of the corresponding journal of the Journal of Citation Reports (JCR) in the field of Economics in the year of publication. ${ }^{1}$ It is wellknown that the Impact Factor (IF) depends on the number of researchers publishing in the area, with this number having grown around two points between the 1990s and today in Economics, favoring younger authors. To correct this bias, we use a Normalized Impact Factor (NIF), defined as follows: for each year, we compute the average impact factor of the set of journals in which any of the authors have published, and divide the impact factor of every journal by this number. To construct the network, we define nodes as the laureates and co-authors, and identify the relations between them generated by common articles, using graphic tools developed in Alvarez et al., (2015). Our paper presents network evidence on all 78 Nobel laureates in Economics between 1969 and 2016, encompassing all publications between 1935 and 2015 included in the Web of Science.

\footnotetext{
${ }^{1}$ The impact of the journal in the year of publication of each paper is a quality measure very frequently used in the academic disciplines. We understand the controversy with the use of the IF (e.g., Bordons et al., 2002; Van-Leeuwen and Moed, 2005; Egghe, 2009) and, consequently, we have employed an improved version, the NIF, that is implemented very efficiently.
} 


\section{Data Collection, Design and Methods}

The data scope consists of all the papers in the Web of Science (WoS) database between 1935 and 2015 in the category of Economics, where we have been able to identify that, at least, one of the authors is a Nobel Prize winner in Economics in the period 1969-2016. The year 1969 was the first year a Nobel in Economics was awarded, with our dataset of papers published between 1935 and 2015 covering a period sufficiently large for our study.

To minimise errors in the identification of authors, we execute a series of tests and crosschecks. To determine that two different signatures or addresses refer to the same individual, we use the Levenshtein distance between strings (Levenshtein, 1996), where distance is defined as the number of insertions or deletions needed to convert one string into another. In this way, we finally obtain a set of 2,150 papers from 284 distinct journals, authored by 1,015 researchers, including the 78 Nobel laureates from 1969 to 2016, and their "first neighbours" (researchers who have signed some paper with them), from 52 different countries. From 1966 to 2015, the average annual number of papers published by all the Economics Nobel Prize winners is 39.66, with an average impact factor of 1.82 per article, while each paper is cited, on average, 93.16 times.

The Web of Science (WoS) database provides few publications from before 1966, so to estimate the importance of this lack of information, we consider the number of entries in Google Scholar for each laureate. Google Scholar is a much more complete database than WoS with respect to the early decades of the past century, although the information is less structured and unified. Applying very similar filters, in order to draw comparisons, we have that, for the laureates of the 1970s and 1980s, the lack of information constitutes around $10-20 \%$ of their total production, which is assumed as a limitation of using the WoS database.

\section{Complex Networks Approach}

Nodes will be the economists under study (the Nobel laureates and their collaborators), and the link between two nodes indicates a joint publication. The weight of the link between two researchers will represent the sum of the NIF of the journals (in the corresponding year) where the common articles were published. 
To represent the network as a positions map, we use force-directed algorithms (Fruchterman et al., 1991), complemented with a Monte Carlo simulation in order to avoid the overlap of nodes, thus, thus obtaining graphs in which researchers with more interaction are closer, forming clusters. This allows us to identify communities of researchers with stronger internal collaborations. In order to gain a precise determination of these communities, and to do so automatically, we use the Walktrap algorithm (Pons and Latapy, 2006) which is very efficient for these networks. It is a hierarchical clustering algorithm based on the idea that short distance random walks tend to stay in the same community. We also define different kinds of centrality measures to quantify which are the most cohesive nodes, or those with the greatest authority (Newman, 2006): the betweenness, which indicates the importance of a node to connect different communities; and the Page Rank centrality, related to the number of important nodes that point to it (Ying et al., 2009).

\section{Network analysis results}

Table 1 presents the top 10 researchers according to their total NIF. The authors involved are experts in microeconomics, macroeconomics, or econometrics, with no clearly predominant focus. When we represent the network formed exclusively by the laureates, taking into account the relations created from the publications authored by two or more of them, we derive the map shown in Figure 1. In this Figure, each bubble (node) corresponds to a laureate and its size is proportional to the NIF of the researcher. The color of the node indicates the belonging to a certain automatically-detected community. One can see that direct collaborations between Nobel laureates are, in general, rare, although there exist certain subgroups of researchers who do form connected clusters. In particular, in the upper region of the figure, there is a rather large connected group, led by Stiglitz, and formed by 18 economists with an economic theory focus, thus including both microeconomists and macroeconomists, such as Smith, Samuelson, Lucas, Maskin, Tirole, Myerson, and Hart, among others. Other lower clusters are led by authors from the mathematical economy area, such as Roth, including Selten, Auman, and Shaply; by Sargent, with two other members, with Sims and Hansen; and, finally, by Arrow, with he being the leader of Solow and McFadden. Following these initial analyses, we can ask whether these individual efforts have something to do with the way collaboration takes place with other researchers, and this is done in the following section. 
(Table 1 about here)

(Figure 1 about here)

We now include in the network, not only the Nobel laureates, but also their coauthors. Figure 2 shows a much richer network, with a total of 1,015 researchers and a larger number of connections. The number of researchers in the large component is 715 (70\% of the nodes), showing that it is a more connected network than the previous one. The modularity is large (0.90), indicating that collaboration between the different groups is still weak. There are certain researchers who build bridges between those groups, and this ability can be quantified through the betweenness. Table 2 shows, among the authors leading the betweenness ranking, Arrow, Modigliani, Miller, and Tirole, who are laureates with a large production, with a significant number of collaborations, and with a very central position in the network. We also observe that the top position is occupied by Grossman, a non-laureate with a smaller production in the network (only the production carried out in collaboration with Nobel winners is considered here for nonlaureates), which gives consistency to the network, because he links important parts of it. Grossman has collaborations with Stiglitz, Hart, and Shiller, among others.

\section{(Figure 2 about here)}

The analysis of the collaboration level of each laureate indicates that there are some authors with very few collaborators (occasionally, none), while others have published with many others. Table 3 shows that Williamson, for instance, has a relatively high production (total NIF of 53.46) and not one coauthor, while Arrow has 101 collaborators and an even higher NIF of 65.42. In order to understand a little more about the collaboration patterns, the average number of authors of an article is 1.689, i.e. each laureate publishes, on average, an article with around 0.7 collaborators. However, the distribution of number of authors per article is rather different.

(Table 3 about here)

Another dimension that measures the importance of a researcher in terms of the role he plays in the network is the page rank, which constitutes a more local definition of centrality than betweenness (it indicates the importance of the node in its neighborhood). As shown in Table 4, the top two page-rank authors are Heckman and Sen, who are 
researchers with an important number of collaborators and a prominent role in their respective communities.

(Table 4 about here)

On the basis of all the above, one question arises: is there a relationship between the production of the researchers and their level of collaboration or their position in the network? When we give a name to each community according to its more productive researcher (the one with the largest NIF), we find that the 10 communities with the larger total production are those presented in Table 5. All are associated with "leaders" who have a significant individual production. However, the internal structure of those communities can be very different. In fact, we note, for example, that Deaton and Arrow are surrounded by many very productive researchers who are not laureates. The communities of Hard and Tirole, on the other hand, include several other laureates (Hart, Shiller, Miller in the first; Tirole, Maskin, Myerson, Holmstroem in the second) with a similar level of supremacy. There are other groups that have a very hierarchical structure, with a powerful leader and a series of collaborators with a secondary role (let us remember, once again, that the production of the non-laureates is not fully considered in this study). Examples of this last case are the communities of Heckmann, Stiglitz, and Smith.

(Table 5 about here)

\section{Conclusions}

We have used Complex Networks techniques to identify the academic leaders among the Nobel Prize laureates in Economics. Starting from the one formed exclusively by the laureates, we find that direct collaborations between them are, in general, rare, though there exist some subgroups of researchers who do form some connected clusters, the largest of them being that formed by authors with an economic theory focus, and another important subgroup formed by mathematical economics. When we add all the coauthors of the laureates, the network becomes denser, appearing as a very large component containing $70 \%$ of the nodes, which means that more than two thirds of the laureates can be connected through only two steps (i.e. one intermediary). With respect to the collaborative level, we find that, in general, a greater level of collaboration is associated with a greater production (at least when the whole impact of an article is 
counted for each author) and can help the authors to cross over into other disciplines or fields of research. Finally, the laureates Deaton, Tirole, Arrow, and Stiglitz are identified as leaders according to the total production (NIF) of their respective networks.

\section{Acknowledgements}

This paper was partially written while Jose Alberto Molina was Visiting Fellow at the Department of Economics of Boston College (US), to which he would like to express his thanks for the hospitality and facilities provided. We thank Web of Science for permission to publish the analysis of these data on the web page research.kampal.com. We want to thank Alfredo Ferrer and J. Ignacio Giménez-Nadal for their help in some aspects of the data treatment and visualization.

\section{Disclosure statement}

No potential conflict of interest was reported by the authors

\section{Funding}

This paper has benefited from funding from the Spanish Ministry of Economy (FIS201565078-C2-2-P) and the Aragon Government (research groups E30_17R and S32_17R)

\section{References}

Alvarez R, Cauhé E., Clemente-gallardo J., Ferrer A., Iñiguez D., Mellado X., Rivero A., Ruiz G., Sanz F., Serrano E., Tarancón A., and Vergara Y., 2015. Analysis of academic productivity based on Complex Networks. Scientometrics 104: 651-672.

Araujo, T., and Fontainha, E., 2017. The specific shapes of gender imbalance in specific authorships: A network approach. Journal of Informetrics 11: 88-102.

Bordons, M., Fernandez, M.T. and Gomez, I., 2002. Advantages and limitations in the use of impact factor measures for the assessment of research performance in a peripheral country. Scientometrics 53(2): 195-206.

Egghe, L., 2009. Mathematical derivation of the impact factor distribution. Journal of Informetrics 3(4): 290-295.

Fruchterman T.M.J., and Reingold E.M., 1991. Graph Drawing by Force-directed. Software: Practice and Experience 21(11): 1129. 
Goyal S., Van Der Leij M.J., and Moraga-González J.L., 2006. Economics: an emerging small world. Journal of Political Economy 114: 403-412.

Levenshtein I., 1996. Binary codes capable of correcting deletions, insertions and reversals. Cybernetics and Control Theory 10: 7076710.

Molina J.A., Ferrer A., Iñiguez D., Rivero A., Ruiz G., and Tarancón A., 2018. Network analysis to measure academic performance in Economics. Empirical Economics DOI: 10.1007/s00181-1546-0.

Newman M.E.J., 2006. Finding community structure in networks using the eigenvectors of matrices. Physical Review E 74(3): 036104.

Polyakov M., Polyakov S., and Iftekhar S., 2017. Does academic collaboration equally benefit impact of research across topics? The case of agricultural, resource, environmental and ecological economics. Scientometrics 113:1385-1405.

Pons P., Latapy M., 2006. Computing communities in large networks using random walks. Journal of Graph Algorithms and Applications 10(2): 191-218.

Rath K., Wohlrabe K., 2016. Recent trends in co-authorship in Economics: evidence from RePEc. Applied Economics Letters 23: 897-902.

Sutter M., Kocher M., 2004. Patterns of co-authorship among Economics Departments in the USA. Applied Economics 36: 327-333.

Van-Leeuwen, Moed, T.H., 2005. Characteristics of journal impact factors: the effects of unitedness and citation distribution on the understanding of journal impact factors. Scientometrics 63(2): 357-371

Ying D., Erjia Y., Frazho A., Caverlee J., 2009. PageRank for ranking authors in cocitation networks. Journal of the American Society for Information Science and Technology 60(11): 2229-2243.

Zuckerman, H., 1967. Nobel laureates in science: patterns of productivity, collaboration, and authorship. American Sociological Review 32: 391-403.

Zuckerman, H., 1977. Scientific elite: Nobel laureates in the United States. Transaction Publishers. 
Table 1

Top 10 Nobel laureates according to their total Normalized Impact Factor (NIF)

\begin{tabular}{lcc}
\hline & $\begin{array}{c}\text { Year } \\
\text { awarded }\end{array}$ & Total NIF \\
\hline Stiglitz, J & 2001 & 140.31 \\
Samuelson, Paul A. & 1970 & 90.80 \\
Deaton, As & 2015 & 81.58 \\
Sargent, T & 2011 & 81.40 \\
Heckman, J. J. & 2000 & 79.99 \\
Smith, Vernom & 2002 & 74.97 \\
Tirole, Jean & 2014 & 67.31 \\
Arrow, K & 1972 & 65.42 \\
Fama, Ef & 2013 & 64.71 \\
Sen, A & 1998 & 59.74 \\
\hline
\end{tabular}




\section{Figure 1}

Nobel laureates network (nodes colored according to the automatically-detected communities)

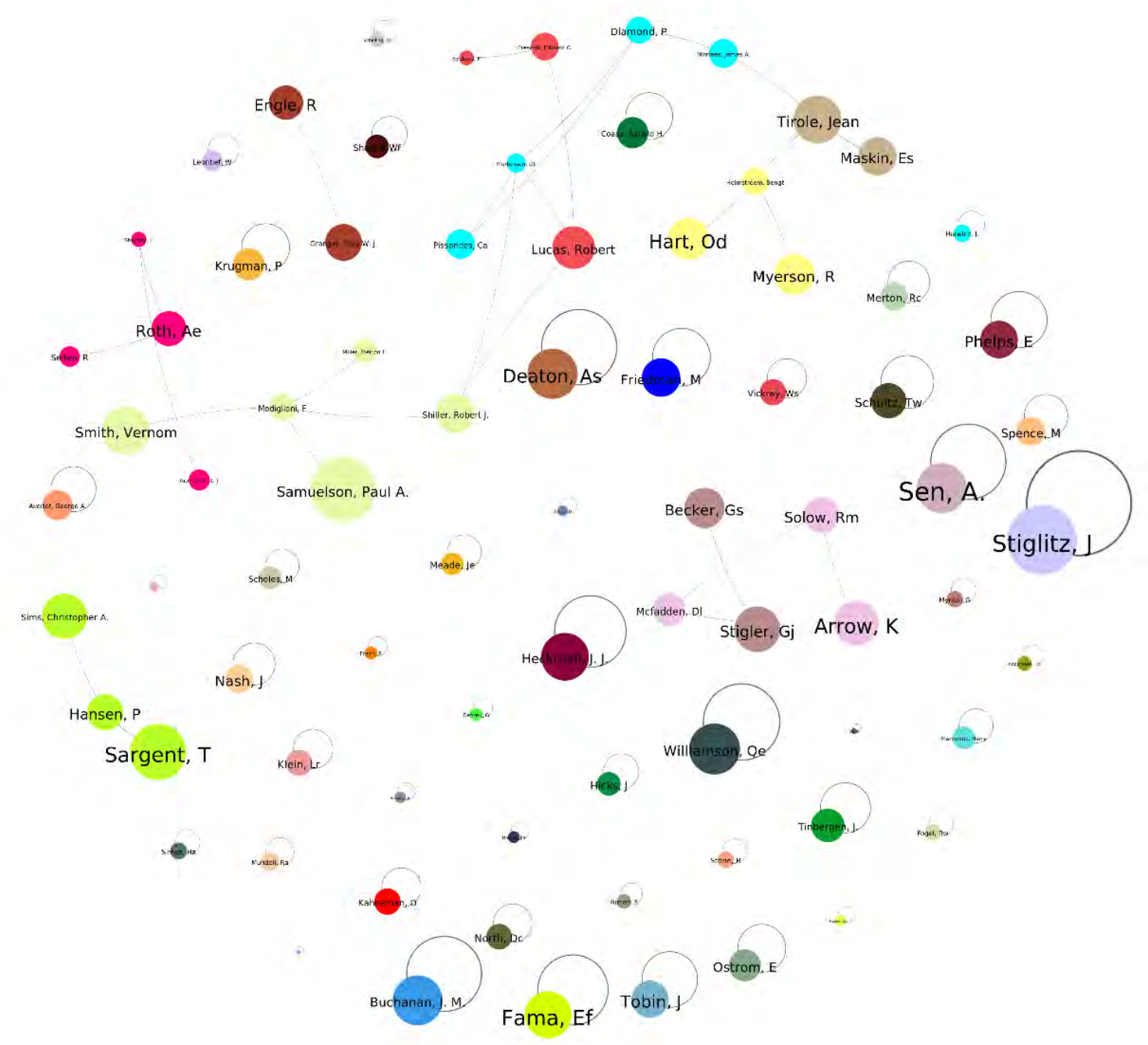




\section{Figure 2}

Network formed by the Nobel laureates (in color) and their collaborators (gray nodes)

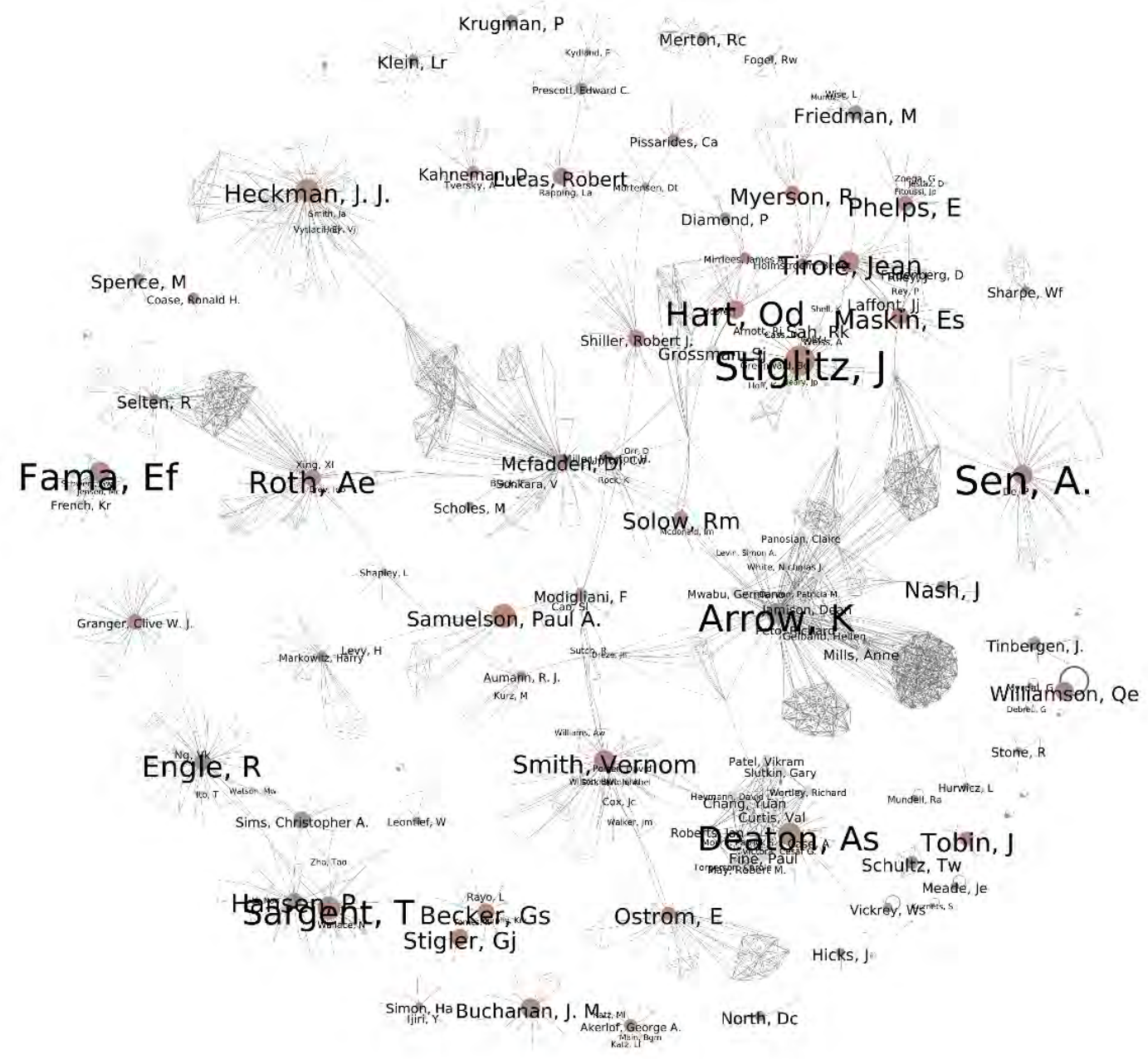


Table 2

Top 10 researchers according to the betweenness in the network Grossman, $\mathrm{Sj} \quad 1.00$

Arrow, K $\quad 0.99$

Modigliani, F $\quad 0.98$

Miller, Merton H. $\quad 0.92$

Tirole, Jean $\quad 0.90$

Holmstroem, Bengt $\quad 0.75$

Hart, Od $\quad 0.75$

McFadden, Dl $\quad 0.69$

Smith, Vernom $\quad 0.57$

Maskin, Es $\quad 0.48$ 


\section{Table 3}

Top 10 laureates according to the number of collaborators Arrow, K 101

Heckman, J. J. $\quad 64$

McFadden, Dl 58

Roth, Ae 50

Smith, Vernom 46

Sen, A. $\quad 45$

Engle, R $\quad 41$

Stiglitz, J $\quad 34$

Selten, R 33

Ostrom, E $\quad 31$ 


\section{Table 4}

Top 10 researchers according to the page rank in the network

\begin{tabular}{ll} 
Heckman, J. J. & 1.00 \\
Sen, A. & 0.97 \\
Smith, Vernom & 0.69 \\
Stiglitz, J & 0.68 \\
Engle, R & 0.66 \\
McFadden, Dl & 0.62 \\
Granger, Clive W. J. & 0.62 \\
Roth, Ae & 0.57 \\
Arrow, K & 0.53 \\
Sargent, T & 0.51 \\
\hline
\end{tabular}




\section{Table 5}

Leaders, production and number of members of the main automatically-detected communities, according to their total NIF

\begin{tabular}{lcc}
\hline Community leader & $\begin{array}{c}\text { Total production (NIF) of } \\
\text { the community }\end{array}$ & Number of members \\
\hline Deaton, As & 275.09 & 29 \\
Tirole, Jean & 256.22 & 57 \\
Arrow, K & 219.14 & 18 \\
Stiglitz, J & 215.47 & 33 \\
Hart, Od & 199.03 & 45 \\
Sargent, T & 175.63 & 39 \\
Heckman, J. J. & 168.29 & 62 \\
McFadden, Dl & 155.69 & 75 \\
Smith, Vernom & 144.51 & 43 \\
Samuelson, Paul A. & 140.12 & 23 \\
\hline
\end{tabular}

